\title{
Civil society participation in REDD+ and FLEGT processes: case study analysis from Cameroon, Ghana, Liberia and the Republic of Congo
}

\section{Poshendra Satyal}

School of International Development, Global Environmental Justice Group, University of East Anglia, Norwich, NR4 7TJ, UK. Tel: +44 (0) 1223294854. Fax: +44 (0) 1603 591170. Email: p.satyal@uea.ac.uk

\begin{abstract}
REDD + (Reducing Emissions from Deforestation and Forest Degradation) and FLEGT (Forest Law Enforcement, Governance and Trade) are two initiatives with roots at an international scale that aim to influence national and local level forest governance. This paper looks to understand how the breadth and depth of participation of different types of actors, most particularly civil society, compares between these initiatives and in what ways the structure of the governance arrangement and/or the focus of commodities may influence this participation. The paper presents findings from an assessment study on the dynamics of participation of civil society actors in REDD+ and FLEGT processes in four countries of Central and Western Africa: Cameroon, Ghana, Liberia and the Republic of Congo. Building on key civil society participation literature, a questionnaire tool was developed and applied in these countries. The analysis is drawn from interviews based on the questionnaire tool, some in-depth interviews and secondary research. The study finds that there is a growing recognition of civil society participation in national policy making of forest governance in the four countries, and a majority of the civil society organisations are participating in REDD + and FLEGT processes. The quality and degree of their participation (that can range from informing to empowering) however, varies between FLEGT and REDD+ (i.e. FLEGT being more accommodative than REDD+), among a diversity of these actors and the studied countries. The difference in participation between REDD+ and FLEGT is related to the design of these two processes, the general lack of time and financial investment and the technical nature of REDD+ consultations. Moreover, FLEGT has been more inclusive and participatory right from the beginning whereas participatory spaces are generally lacking in REDD+ process, most particularly in its initial stages. As REDD+ and FLEGT processes are being consolidated in these countries and worldwide, this paper provides several avenues of interventions needed to address gaps on participation, such as strengthening participatory platforms, addressing representation deficit for community groups and focusing on capacity building of civil society actors.
\end{abstract}

Key words: civil society; participation; REDD+; FLEGT; policy making; Africa

\section{Introduction}

Forest governance is increasingly responding to global claims over forests as a central strategy to address the worldwide problem of deforestation, illegal logging and climate change. With increased globalisation of forest governance through polycentric and multi-level mechanisms, the ways in which global initiatives are domesticated through national forest policy making are more important than ever, including how different actors are involved in the process (Dawson et al., 2018; Maryudi and Sahide, 2017; Myers et al., 2018). In this paper, I explore two initiatives with roots at an international scale, that aim to influence national and local level forest governance: (a) Reducing Emissions from Deforestation and Forest Degradation and conservation, sustainable management of forests and enhance of forest carbon stocks (REDD+), an international policy framework that seeks to incentivise enhanced forest management in developing countries; and (b) Forest Law Enforcement, Governance and Trade (FLEGT), an initiative developed by the European Union to 
address the global concerns of illegal logging by strengthening legal forest management, improving governance and encouraging trade in legally sourced timber. In particular, my aim is to understand how the breadth and depth of participation of different types of actors, most particularly civil society, compares between these initiatives and in what ways the structure of the governance arrangement and/or the focus of commodities may influence this participation.

Comparing REDD+ and FLEGT is nothing new. Several studies have attempted to compare and contrast them in different ways. A number of publications have analysed possibilities for REDD+ and FLEGT to complement or conflict with one another (Broekhoven, 2014; Dooley and Ozinga, 2011; Haijar, 2014; Phúc et al., 2012; Späth, 2015; Ochieng et al., 2013; Sikor and To, 2014). For example, Mustalahti et al. (2017) examined civil society participation in REDD+ and FLEGT in Lao PDR, suggesting the vital importance of participation to these processes, but as Mustalahti et al. (2017) point out, REDD+ and FLEGT share a fundamental concern for forest degradation, deforestation, and emphasise the governance issues that underpin these issues. There are, however, several governance features of these arrangements that make them distinct from one another. For example, a point of comparison between REDD+ and FLEGT that can also influence participation of different actors is the object of sale. Compared with FLEGT, which is concerned with the sale of timber, the idea of carbon credit and being paid to 'sell air' under REDD+ mechanism is relatively abstract for many actors. This highlights, to some extent, the complexities of operationalising participation under carbon-dominated forest management.

Proponents of REDD+ and FLEGT espouse participation by a range of actors in tropical countries in the development of the prospective initiatives. For example, 'full and effective' participation of non-state actors has been highlighted within the REDD+ safeguards of the UN-REDD programme and the World Bank's Forest Carbon Partnership Facility (FCPF) (FCPF and UN-REDD, 2012). The REDD+ safeguards provide guidelines on issues such as stakeholder identification, clear procedures, social/cultural appropriateness, information sharing, capacity building, and grievance resolution. Similarly, FLEGT (and specifically the Voluntary Partnership Agreements or VPAs) aim to foster actor participation in decision-making, both in the VPA process itself and as a result of the commitments that the parties make (Fern, 2014a; Commission of European Communities, 2003).

While there is an emerging body of literature on assessment of participation of different stakeholders in national REDD+ development (for example, Pham et al., 2014; Atela et al., 2016; Brochaus et al., 2014; Dawson et al., 2018; Satyal et al., 2018) and FLEGT VPA (Wodschow et al., 2017; Overdevest and Zeitlin, 2014), there are comparatively limited studies that link and compare REDD+ and FLEGT policy making and include the synergies between these two processes (see Hajjar, 2015; Tegegne et al., 2017 as exceptions). In particular, the impacts of REDD+ and FLEGT initiatives on forest governance reform and civil society participation in Central and Western Africa is not well understood.

This paper interrogates whether and how REDD+ and FLEGT processes have induced changes in the region's forest governance with regards to civil society participation. It focuses on an assessment of the quality of civil society participation in the national policy making processes of REDD+ and FLEGT VPAs in Cameroon, Ghana, Liberia and the Republic of Congo. ${ }^{1}$ In order to analyse civil society participation, three main variables are considered: (i) who participates, (ii) when they participate, and (iii) how they participate (i.e. their degree of participation that can range from information sharing to empowerment). Building on key literature on civil society participation

\footnotetext{
${ }^{1}$ The focus of this study is on civil society participation in policy processes and whether or not their positions are reflected in the policy outcomes. For this, REDD+ processes that were assessed in the four countries included respectively: development and adoption of the RPIN (Readiness Plan Idea Note), the REDD+ strategy, RPP (Readiness Preparation Proposal) and for Cameroon, Ghana and Republic of Congo, the ER-PIN (Emissions Reduction Project Idea Note). The focus of FLEGT process was on VPA development and negotiation.
} 
(Section 2), a questionnaire tool was developed and applied in the four countries. The analysis is drawn from interviews based on the questionnaire tool, some in-depth interviews and secondary research.

The four countries were chosen due to the advanced stages of REDD+ and FLEGT in these countries. The study was part of a larger project linking FLEGT and REDD $+{ }^{2}$ To date, FLEGT VPA implementation and REDD+ negotiations are not integrated, as they are happening in parallel and are overseen by different Ministries and, in some countries, different civil society organisations (CSOs). The selection of countries from both West and Central Africa was also due to the proximity of these countries to each other that allowed them to be considered a geographically coherent area facing similar challenges but with different experiences that are important to share.

The paper is structured as follows. Section 2 provides the conceptual framework. Section 3 provides the research methodology. Section 4 provides country-by-country assessment of civil society participation in REDD+ and FLEGT VPA. The focus is on the mechanism of participation (i.e. how actors get involved and participate in decision-making through FLEGT VPA and REDD+ structures and processes) and the dynamics of participation (nature and degree of their participation). Section 5 provides an overall discussion and conclusion is provided in Section 5.

\section{Conceptual framework}

This paper is grounded on the notion of participation drawing from key literature on the topic, as a basis for analysing the principles and practices of civil society participation in the REDD+ and FLEGT processes (see also, Satyal et al., 2018, which applies similar approach).

Although participation means different things to different people, it is most commonly defined as "a process through which stakeholders influence and share control over development initiatives, decisions and resources which affect them" (World Bank, 1998, p. 3). Although 'participation' in forest governance has a feel-good quality, it is interpreted and practiced in very different ways. Participation, including that of non-state actors, is considered vital for the success of policy processes that aim to address both social and environmental objectives and their implementation frameworks (Daviet, 2011; Forsyth, 2010). In particular, participation of civil society, indigenous peoples and local communities is often highlighted as one of the key issues of public discourse on forest governance, with emphasis on 'full' and 'effective' participation (Lawlor et al., 2013; Pham et al., 2014; Atela et al., 2016). Some civil society groups argue that an empowered civil society with the capacity to access and analyse information, to monitor forest management and to advocate and hold governments accountable can contribute to improving forest governance (e.g. Fern, 2013, 2014a, 2014b). The extent to which some countries have a clear mechanism for engaging civil society actors and local communities is often questionable.

Participation is emphasised for the reasons of democratic necessity, management legitimacy, sharing of knowledge and understanding, and transparency and accountability (Stoll-Kleemann and O'Riordan, 2002). It benefits decision-making processes by increasing likelihood of reaching practical and credible decisions that reflect a broad consensus among actors (IAIA, 2006; Osmani, 2008). It may also promote fairness in policy-making by improving relations between actors that previously had poor relations, and thus reduce conflict. However, critics warn that participation should not be seen as a universal panacea that promotes social justice (Cooke and Kothari, 2001; Cleaver, 1999; Faysse, 2006). Participation processes are also very often expensive, time consuming and sometimes involve stakeholders who are not representative or it empowers those

\footnotetext{
${ }^{2}$ This national case study complemented work by other project partners who looked at participation at the 'project' level - individual concessions or other investments in logging, large-scale agriculture or REDD+ sites.
} 
who are already influential (Cooke and Kothari, 2001; Cornwall, 2008).

Various studies have used the main ideas from the mainstream participation literature and applied them to assess the provision of participation and power dynamics in forest policy formulation and implementation (see Maryudi and Sahide, 2017). In particular, there is a plethora of empirical studies assessing community participation in forest management (for example, Shrestha and Shrestha 2017; Green and Lund, 2015; Secco et al., 2014). There are also growing empirical studies (including recent publications in the Forest Policy and Economics) that examine the effectiveness of participatory processes in the formulation of national and regional forest policies or forestry reforms (Balest et al., 2017; Johansson, 2016; Tikkanen, 2017; Weber, 2017; Lund, 2015; Tender and Kaimre, 2017); implementation of conservation programmes (Brescancin et al., 2017) or in the urban forest planning process (Kangas et al., 2014; Kozova et al., 2017).

Different methodologies and criteria have been used to assess multi-stakeholder processes, specifically at policy development level. Key aspects to evaluate dynamics of participation include: structure of participatory process; types of diverse stakeholders (for example, based on their relevance, interests and influence in decision making); skills and knowledge of participants (including capacity and competence); role of facilitator; level of participation (ranging from information-sharing to empowerment) (Arnstein, 1967); intensity of participation (symbolic representation or substantive deliberation); timing and frequency (early involvement, one-off or continuous participation); and goal (including influence both in policy process as well as the outcome) (Balest et al., 2017; Kozova et al., 2017; Kangas et al., 2014; Satyal et al., 2018; Teder and Kaimre, 2017). There are also several other factors for successful participation such as access to the process, transparency and accountability, provision of timely and easy access to information, policy coherence, level of conflict or trust among the stakeholders, availability of good support, and enabling social conditions (Brescancin et al., 2017; Atela et al., 2016; Kangas et al., 2014; Secco et al., 2014).

Drawing on these insights from literature and methodological guidance on participation, the conceptual framework and the questionnaire tool (Annex A) for this study focuses on three key elements of participation: (a) who participates?; (b) when they participate?; and (c) to what degree they participate?

The first key element is to understand who participates in the policy making processes and the diversity of actors who are affected by, or can affect the policymaking (IAIA, 2006; Faysse, 2006). It is important to pay closer attention to 'who is participating, in what and for whose benefit' (Cornwall, 2008, p. 269). In the assessment of civil society participation, it is obvious that it is the civil society actors of various types that need to be understood and identified, including mapping of their interests, influence and relationships with the government and each other (White, 1996; Weber, 2017; Atela, 2016). Civil society is defined as the network of individuals and groups (both formal and informal) - their connections, social norms and practices - that comprise the activities of a society and that are separate from its state and market institutions (IAIA, 2006). It is thus the aggregate of non-governmental organisations (NGOs) and institutions that manifest the interests and will of citizens and are independent of the government (Gramberger, 2001). It is to be noted that civil societies and the organisations that work to represent them, CSOs, are (re)born and evolve according to a complex series of variables in different country and regional settings (Hughes and Atampugre, 2005). It also needs to be acknowledged that there is a wide diversity with respect to capacities, nature, roles of, and relationships with the governments.

Related to who participates is which activities they participate in and at which stages in the process (Cornwall, 2008, p. 280). Hence the second concern is related to the time. Participation differs from one-off event to events occurring continuously at different phases of a policy cycle (World Bank, 
1998; Maier et al., 2014). Hence it is necessary to evaluate the timing of participation, referring to the phase in the policy process in which stakeholders are involved, these range from the phase of problem formulation, process design, selecting opinions and outcomes, information gathering and synthesis, decision, to implementation and evaluation (Maier et al., 2014; Gramberger, 2001). While there are various stages in a policy cycle, the focus of this study is in the phases of agenda setting, policy formulation, and decision-making. Particularly, 'agenda setting' can be crucial, as often governments, the private sector and forest-dependent communities have quite different ideas about what is a priority. It also needs to be noted that participation can change over time, with a tendency of 'participation fatigue' in the later stages amid actor's continued concerns of 'what's in it for me' (Lindstad, 2017).

The third question is concerning the degree at which participation occurs. There are various degrees of participation, ranging from simply being told about a policy process to having a say and being able to influence outcomes (Arnstein, 1967; Agarwal, 2001, 2010; Satyal et al., 2018). This paper assesses different degrees of participation based on a 5-scale indicator, from Informing (Very High) to Empowering (Very Low) (see Table 1). Related to the degree/level of participation is the question of 'who decides what is participation' and 'on whose terms' i.e. an analysis of symmetries of power, highlighting the intersections between inclusion/exclusion and involvement and influence (Cornwall, 2008, p. 276; Maryudi and Sahide, 2017).

Table 1. Different types and degrees of participation

\begin{tabular}{|l|l|l|}
\hline $\begin{array}{l}\text { Type of } \\
\text { participation }\end{array}$ & $\begin{array}{l}\text { Degree of } \\
\text { participation/ } \\
\text { Level of } \\
\text { influence }\end{array}$ & Description \\
\hline Informing & Very Low & $\begin{array}{l}\text { One-way flow; being informed of decisions ex post } \\
\text { facto; or attending meetings and listening in on } \\
\text { decision-making, without speaking up; people's } \\
\text { feedback is minimal or non- existent. }\end{array}$ \\
\hline Consulting & Low & $\begin{array}{l}\text { Two-way flow; being asked an opinion on specific } \\
\text { matters without guarantee of influencing decisions. }\end{array}$ \\
\hline Involving & Medium & Being asked or volunteering to undertake specific tasks. \\
\hline Collaborating & High & $\begin{array}{l}\text { Increasing control over decision-making; forming } \\
\text { groups of primary stakeholders to participate in the } \\
\text { discussion and analysis of predetermined objectives set. }\end{array}$ \\
\hline Empowering & Very High & $\begin{array}{l}\text { Having a voice and influence in the decisions; } \\
\text { ownership and control of the process rest in the hands of } \\
\text { the primary stakeholders. }\end{array}$ \\
\hline
\end{tabular}

Source: Arnstein, 1967; Agarwal, 2001, 2010; Secco et al., 2014.

Finally, in order to understand the participatory processes and deliberative spaces created under REDD+ and FLEGT, it is also useful to understand the diverse possible ways (e.g. direct, semidirect or indirect) participation can occur (e.g. representation of some NGOs by their federations through working groups; or understanding who these civil societies represent or are accountable to (Borrinni-Feyerabend, 1997; Weber, 2017).

\section{Methodology}

The assessment of civil society participation was conducted in two phases: (a) development of a questionnaire tool to assess participation (March-September 2015); and (b) application of the tool in the four countries (January-April 2016). In the first phase, key literature on civil society 
participation was reviewed for the purpose of developing the tool, this was refined after a review by at least one $\mathrm{CSO}$ in each of the four countries. Interviews were conducted using the checklist in the questionnaire tool (see Annex A), however there was also some flexibility during the interviews to cover additional topics of interest. The second phase consisted of data collection gathered by contacting key informants, mainly from various CSOs but also from government agencies (in Liberia), representatives of community groups and international NGOs and by organising individual and focus group discussions with them. For this, a preliminary stakeholder analysis based on their relevance, interest and influence was carried out to identify key civil society actors for interviews in each of the countries of study. Attempts were made to have a wide variety of civil society groups in the sample so as to reflect their diversity and also their varied experiences and views. In total, 42 civil society members were interviewed in the four countries and there were 36 quantitative responses: 9 from Cameroon, 9 from Ghana, 10 from Liberia and 8 from the Republic of Congo. ${ }^{3}$ During the field study in Ghana and Liberia, there was also an opportunity to witness participation of CSOs in national forums.

The civil society members included in the study consisted of a variety of individuals and came from a wide range of organisations. Some of these interviewees were members of multi-stakeholder forums in their country. These organisations are all working on areas of forest governance and/or REDD+ and FLEGT VPA, however some were more involved in one area than the other. There were also few representatives who had not participated or had not been included in REDD+ and/or FLEGT meetings. The paper thus attempts to capture the diverse experience of these actors and seeks to provide a thorough analysis of civil society participation in the four countries.

\section{Results: civil society participation in REDD+ and FLEGT processes in the four countries of study}

Arguably, civil society and CSOs are critical partners and actors in the public policy sphere and as such, are essential in the protection of fundamental freedoms and the development of democratic governance (CIVICUS, 2014; Fern, 2014a). In the four countries, they generally act as independent watchdogs, some working as advocates of human rights; others working as service providers, often responding to the needs of communities at the grassroots level (Jumah, 2011; McKeown and Mulbah, 2007; Agora Consulting, 2015). However, with a diversity of CSOs focusing on different specific areas, they are not always unified nor have they always shared interests.

\section{Cameroon}

Civil society movements in Cameroon, especially in the forest and environmental domain sprouted in the 1990s with the passing of the law on Freedom of Association and with reforms in the forestry sector (Agora Consulting, 2015). Since then, civil society is generally recognised as being more vociferous. The role and place of civil society in the development, monitoring of the implementation and evaluation of public policies is inscribed in the fifth component of the National Governance Programme i.e. 'the participation of citizens and the civil society in the management of public affairs' (Agora Consulting, 2015). To render this provision operational, several platforms for dialogue between the civil society and the government have been established in recent years. Despite the progress in CSO participation in public affairs in Cameroon, there are a number of limitations to their participation: the problems of legitimacy and representation; the quality of the contribution of CSO representatives (which is sometimes undermined due to their low expertise);

\footnotetext{
${ }^{3}$ These interviewees were selected from a wide range of CSOs which were identified as key target groups for the larger project, which included NGO coalitions in the four countries, consisting of 39 NGOs in Ghana, 18 in Liberia, 37 in Cameroon and 22 in the Republic of Congo. Through existing networks and project partners, snowball sampling was used to gain access to these actors. It is noted that only in Liberia government organisations could be contacted; this made it impossible to draw conclusions about the views of government officials and policy makers in other countries. Furthermore, due to four cases involved, there was limited space in the paper to discuss the influence of larger political economy and history of forestry reform on participation in these countries. However, useful references and recent literature have been signposted for interested readers.
} 
the lack of recognition on the part of some public sector actors (who are still somewhat reluctant to work with CSOs); lack of trust among the stakeholders, and non-existence of feedback mechanisms to CSO networks and platforms by their designated representatives (Agora Consulting, 2015; Tegegne et al., 2017; Wodschow et al., 2016).

In Cameroon, CSOs have been represented in FLEGT VPA and REDD+ policy processes mainly through two platforms: (a) Community and Forests Platform (CFP); and (b) REDD+ and Climate Change Platform (PFNREDD \& CC). The PFNREDD \& CC claims to be a broad grassroots network of more than 73 CSOs and 429 national and community based organisations and is recognised in the Readiness Preparation Proposal (RPP) as an interlocutor between government and civil society. It is also a member of the national REDD+ steering committee. The CFP represents more than 50 national, local and community based CSOs working on forest and peoples' rights issues in Cameroon. The platform acted as an official CSO representative during the VPA process. It sat on the negotiation table since 2007 and in other working groups till the signing of the agreement in 2010 and currently occupies seats in the national implementation and follow-up committee for the VPA. However, CFP was not directly involved or invited to participate in the REDD + process but has been carrying out advocacy on REDD+ (e.g. writing a position paper).

\section{Ghana}

Since the advent of multiparty democracy in 1992, Ghana's thriving democracy, good governance practice and vibrant media have provided a favourable environment for a moderately strong civil society in the country (CIVICUS, 2014; Jumah, 2011). There are more than 3,000 NGOs registered under various Acts and tens of thousands of registered self-help groups (CIVICUS, 2014). CSOs in Ghana exist at four levels: community groups, community-based organisations, national CSOs, and networks and coalitions. Some environment and development CSOs are members of, or have established, coalitions and networks through various platforms. CSO activities in Ghana have evolved from service delivery to active public policy advocacy (Jumah, 2011). These CSOs attempt to influence public policy through their demand for involvement in the early stages of policy formulation, advocacy, and are trying to influence the choices made by political actors (ibid.). CSOs are free to publish their research reports, share their evidence-based analysis, comment or criticize government policy and interventions without fear of being victimized (CIVICUS, 2014). However, there are some identified weaknesses and challenges too. These include: existence of some bogus CSOs; lack of downward accountability; lack of local ownership of decisions and actions; competition for visibility and funds; lack of financial sustainability; and capacity deficit of organisation and staff (Jumah, 2011; Carlsen, 2014).

Forest Watch and Kasa Ghana are the two main platforms for the CSOs to discuss pertinent issues on natural resources (including issues of forest governance, REDD+ and VPA). Forest Watch acts as the national forum of over forty CSOs and individuals working for the rights of poor forest users and has been doing policy advocacy on land tenure, community development and forest governance issues since 2004. In particular, it campaigns for greater civil society mobilisation and democratic stakeholder participation in forest policy making and management, particularly for forest dependent communities. On the other hand, Kasa Ghana claims to have over 100 networks, coalitions and partners, however it strategically focuses advocacy works on seven key areas (forest, oil and gas, fisheries, water and sanitation, mining, environment and climate change, and land). Its mission is to "coordinate effective participation in responsible environment and natural resource governance for the realization of rights of people, particularly the marginalised" (KASA Ghana, 2016).

In terms of the VPA process, negotiations started in 2005 and agreements were finalised and signed in 2009. The REDD+ process started in 2009 but the CSOs' involvement in the development of REDD + documents began only after few years. The Emissions Reduction Project Idea Note (ER- 
PIN) had already been developed when civil society members were asked for their feedbacks; they were consulted during the development of the RPP and contributed to discussion during the development of REDD+ safeguards. In fact, some CSOs such as Civic Response, that also coordinates Forest Watch, had facilitated the organisation of national and local forest fora that were also used for REDD+ consultations in the beginning.

CSOs are included in steering committees and working groups in both the VPA and REDD+ processes. For the VPA, these include: the VPA steering committee, the multi-stakeholder implementation committee, and the Timber Validation Committee (under the Forestry Commission Ghana). For REDD+, there are the REDD+ steering committee (since 2010), and Strategic Environment and Social Assessment (SESA) Working Group.

\section{Liberia}

Liberia is a fledgling democracy that came out of war in 2003 (Atuobi, 2010). The country's economic and political stability was threatened again due to the Ebola epidemic in 2010 that continued until 2015. Civil society has been instrumental in promoting peace, monitoring government accountability and policy development as well as in advocacy and service delivery (McKeown and Mulbah, 2007). It is in this context of peace building that civil society actors in Liberia saw themselves as key partners and continued to demand more space from the state (Atuobi, 2010). Some sections of civil society have also been successful in promoting their agenda through their participation in the country's policy arena, in particular women's organisations and environmental groups. Among other issues, there is a capacity deficit in areas such as leadership and organisation development among the CSOs in Liberia. This is also partly due to the fact that some civil society leaders have become part of the government or consultants (McKeown and Mulbah, 2007). Many of the CSOs in Liberia are also connected to community groups that form their constituents. These CSOs are also networked through a common platform - the NGO Coalition, which brings together fifteen different organisations working in a variety of areas. There are also other platforms dealing with specific issues.

VPA process started in 2009 and agreements were signed in 2012 and ratified in 2014. In the process, a number of institutions were involved, including three CSOs from the NGO Coalition. VPA in Liberia has a working group and steering committee. These CSOs are also represented in the VPA steering committee ( 3 out of 15 members are CSOs). In the REDD+ process, there are both a working group and a steering committee; civil society members are also part of these organs. Few (mainly international) CSOs (e.g. Fauna and Flora International, Global Witness and Save My Future Foundation) were involved in the REDD+ process (e.g. development of RPP and REDD+ strategy). Some national CSOs such as Green Advocates, Sustainable Development Institute and Society for Conservation of Nature in Liberia have become active members in the REDD+ Technical Working Group. These CSOs are also part of the SESA Working Group. There are several mechanisms to oversee consultations with regard to REDD+ and forest governance: Environment and Social Monitoring Framework, Safeguards Information Framework, Community Forestry Working Group, REDD+ Technical Working Group, SESA Working Group, and Concessions Working Group. Other available institutional mechanisms include: Climate Change Steering Committee and Civil Society Dialogue platform.

\section{Republic of Congo}

The Republic of Congo has experienced civil wars which have impacted on the country's social fabric. Civil society played a very active role in the democratisation process of the country in the early 1990s, demanding freedom of expression and the move from a single party to multiparty politics (CIVICUS, 2014; Fern, 2013). Civil society has been very strong on human rights agenda. 
It is in this background of their work on human rights, relief and other rural development support that the CSOs have taken up issues of natural resources, forest governance and environment management. There are several civil society platforms and networks in the country, including some working on the issue of transparency in natural resources management.

Civil society participation at the VPA and REDD+ processes in the country takes place mainly through two platforms: (a) the FLEGT platform (PGDF) that was initially set up to improve forest governance but later decided to use the VPA and forest reforms as levers to provoke change (same strategy as the CFP in Cameroon); and (b) the REDD platform (CACO-REDD). Within the framework of VPA negotiations, PGDF representing the CSOs also comprises representatives of indigenous peoples and local communities. The REDD+ platform, CACO-REDD also has two components one for civil society organisations and one for indigenous peoples.

CSOs in the Republic of Congo participated in the negotiation of the VPA, through the decisionmaking bodies, such as the National Consultative Group and Joint Working Group. Formal negotiations started in June 2008 and the VPA was signed in May 2009. In the VPA negotiation, a number of issues were discussed in the legality grid, including mechanism of participation; Free Prior Informed Consent (FPIC); and benefit sharing. While a number of CSOs participated in the negotiations, communities and indigenous peoples were not directly represented (other than through a few CSOs working with indigenous peoples, or composed of indigenous peoples participating in the PGDF platform; see Fern, 2014b).

CSOs have also participated in the process of revising forest law and elaboration of forest policies, including RPP and other technical meetings on REDD+ (e.g. legal, safeguard and secretarial groups). However, some CSOs argue that they were not able to participate in the drafting of REDD+ documents but only to validate these documents (e.g. RPP) which were written by consultants. In their views, there was almost no CSO participation in REDD+ meetings that followed (e.g. elaboration of ER-PIN in 2014), hence they had to publish position papers to raise their concerns.

I provide below the findings from the assessment study, highlighting the experience of participation of different CSOs in FLEGT and REDD+ processes in the four countries.

\subsection{Country-by-country assessment}

\section{Cameroon}

As discussed earlier, civil society participation in FLEGT VPA and REDD+ processes in Cameroon takes place mainly through two platforms, the CFP and PFNREDD \& CC. The experience of participation for the two platform members vary greatly. When asked whether the CSOs were fairly represented in the REDD+ and FLEGT VPA processes, the interviewees from these platforms had mixed opinions. The PFNREDD \& CC, with a sympathetic view to the government efforts, sees a relatively high level of representation of civil society in the REDD+ process. On the other hand, CFP members see a relatively low representation of CSOs in REDD + and a relatively high participation in the VPA process.

The PFNREDD \& CC thinks that there are mechanisms to incorporate views of the civil society and marginalised forest communities (e.g. through the flexible institutional structure of the REDD+ steering committee). On the other hand, the CFP is critical of the REDD+ process. For example, its position paper on the Cameroon's ER-PIN highlights the poor quality of stakeholder engagement, most particularly with the local communities and indigenous peoples. Although Cameroon adopted national FPIC guidelines that guide effective participation of all stakeholders, including at the 
community level, the ER-PIN process failed to implement these guidelines and communities did not have the opportunity to directly participate in the development of the document. ${ }^{4}$

Both platforms acknowledge that some important stakeholder groups have been missed in the REDD+ process, including women, indigenous people, local communities, small forest enterprises, and people from some ecological zones (e.g. savannah). Local communities and indigenous people were left out partly because the CSOs were weakly organised or had insufficient technical, financial, and material means (see also Tegegne et al., 2017; Overdevest and Zeitlin, 2014). Similarly, there was little or no participation of the CSOs from the grassroots and provincial levels.

CSOs have participated in various VPA and REDD+ meetings, as they were involved in the reflection and adoption of the documents being developed. However, the invitation for their involvement has not always been evident. At times, civil society had to push to be invited. Invitations came very late which made effective participation difficult.

In terms of VPA, both platforms agree that the degree of stakeholder participation in the VPA process has been one of the greatest strengths of the FLEGT initiative in the country. CSOs were mainly involved in the development of the VPA legality grid, preparation of agendas, and constitution of commissions, committees and working groups. They acknowledge the inclusive nature of the VPA in which civil society members were invited to take part right from the beginning and the fact that their views are taken seriously in the meetings. Also, both civil society and indigenous peoples have their official representations in the VPA implementation, however there was no representation of indigenous peoples during the VPA negotiation.

For REDD +, CSOs participated in training on formulation of safeguard proposals, composition of REDD+ organs, and consultation with local forest communities. While many of the interviewees did not participate directly in the beginning, they have recently been invited to participate in the consultation. However, CSO have only one place among the 17 members of the national steering committee of REDD+. There is also only one representative for NGOs and one for indigenous peoples out of 14 members of the VPA national follow-up committee. Some interviewees think that participation of CSOs, particularly in REDD+ is still insignificant, as the meetings are dominated by members of different government ministries, World Bank, consultant groups and INGOs. Additionally, in the national REDD+ steering committee and VPA follow-up committee where civil society have official representations, the decisions are generally taken by consensus and sometimes by vote. Since the CSOs are in minority, as many interviewees argue, they hardly can influence decisions. In those cases, when decisions are taken by a simple majority, CSOs have to use advocacy outside the institutions or meetings to push their positions. For example, CFP had advocated separately to push their agenda in REDD+ process.

Participation is considered by most interviewees as an $a d$ hoc process that stops and starts (i.e. short-term) in the case of REDD+ (for 8 out of 9 responses). On the other hand, it is considered as ongoing (medium to long term) in the VPA process (for 7 out of 9 responses). To illustrate their experience of continued participation in FLEGT VPA, CFP members provided an example. In 2012 the CFP on behalf of CSOs carried out an evaluation of the implementation of the VPAs in Cameroon and observed that the preparatory phase was weak. They also observed weak implementation of Annex 7 (i.e. information to be put at the disposal of public) and continued

\footnotetext{
${ }^{4}$ CFP further questions the limited time available for collecting feedback on the document: "Most of (civil society) organisations criticized the initiative of asking only for constructive comments within a one week time frame as a way for the government to negatively influence the participation of all the stakeholders. In fact, the government took eight months to improve the document but just gave one week for comments from CSOs on a technical document of more than a hundred pages and only written in English when a lot of CSOs do not always have high level of English proficiency staff to fully understand it. How then can CSOs have a fundamental contribution? How can such document be validated without a certain level of participation? Why didn't the government take time to consult and ensure the participation of the CSOs and build a robust ER-PIN for a resubmission?" For more details, see: https://www.forestcarbonpartnership.org/sites/fcp/files/2016/May/Position\%20Note\%20CFP final.pdf (accessed October 2016)
} 
illegal exploitation of forests. After four years of advocacy and engagement, in their most recent assessment in 2016 they found out there was good progress in the implementation of Annex 7, as 80 percent of the documents were published online, illustrating improved access to information achieved through continuous advocacy and effective civil society participation. In 2015, the CFP also participated actively in the evaluation of the FLEGT action plan conducted amongst others in Cameroon by a team of international evaluators. The platform also assessed its participation in the VPA process and formulated a set of recommendations for the future of the FLEGT action plan, as reflected in its final evaluation.

According to the interviewees, the frequency at which CSOs are informed of consultation in the VPA process ranges from mostly (6 responses) to always (3) whereas in REDD+ it is often (8 responses) to never (1). Many interviewees also complain about the way and the timing when they are informed, this is more important than the frequency at which they are asked to participate. For example, in the REDD+ process, documents in English have been shared for consultation with CSO representatives very late in the process; this has hindered their participation.

On the question of whether adequate and accessible information on REDD+ and FLEGT VPA processes and meetings is provided in a timely manner to the CSOs and indigenous peoples, 5 interviewees responded yes and 4 no. In particular, poor preparation and late notification of a meeting is common. A CSO representative engaged in both the VPA and REDD+ processes responds:

Access to information and the quality of information made available is always a problem. In the case of the VPA process, it happens often that the CSOs are invited only to approve a document and they only received the document during the meeting or a day before. In the REDD+ process, it is not inclusive or open to many stakeholders and the quality of information is often worse than in the VPA; the discussion is very technical with highly vague concepts without a national definition: additionality, leakage, offsets etc, which are difficult to understand for many of us.

Most interviewees consider their participation in FLEGT VPA as collaborating (high), even though they acknowledge that collaboration could be questioned at times when opinions on some issues are highly divergent. Some CSOs think that their views were considered both in the VPA agreement and in the proposals submitted in respect of the forest law reforms, and more specifically taking into account the social, environmental and governance aspects. ${ }^{5}$ Some examples in the VPA process where their views were widely discussed and considered include: issues of the rights of communities and CSOs to participate in the decision-making, issue of transparency, special disposition (Annex 7 of the VPA), and community capacity building in forest monitoring.

On the other hand, the level of participation in REDD+ is classified as low (informing) by most interviewees (except for the PFNREDD \& CC). As one interviewee from the CFP charges that the participation in REDD+ is "a deliberate action of the government to get approved what they have already decided" and the CSO participation is only "used for validation purpose". Among the interviewees, only the PFNREDD \& CC think that their participation is high (collaborating), as they have contributed actively in the validation of the RPP and elaboration of the national REDD+ strategy and ER-PIN. However, the CFP argues that the views of CSOs are hardly sought in the elaboration of REDD+ documents; they were only considered after strong advocacy actions by the CSOs.

\footnotetext{
${ }^{5}$ However, it is still premature to judge the impact of CSOs suggestions on the forest law reform. There is still uncertainty about how the final text of the new forest law will look like and to what extent the positions of civil society are taken on board.
} 
Overall, most interviewees are thus satisfied (5 responses) to neither satisfied nor dissatisfied (4 responses) with their experience of the VPA process. Members from the CFP think that their participation, particularly in the VPA has had a positive impact on forest governance in recent years in Cameroon. In the case of REDD+ process, civil society's experience is overall unsatisfied (7 responses), except for the interviewees from PFNREDD \& CC who have a positive assessment of their experience (satisfied). Members from both platforms acknowledge that more needs to be done to enhance the participation of women, local communities and indigenous people in REDD+ process.

\section{Ghana}

In general, most interviewees agree that civil society participation in forest policy processes has improved over the years in Ghana. However, concerns are raised about the nature of their representation and participation. Although civil society members are included in the working groups and committees on both VPA and REDD+ in Ghana, some interviewees question whether it is adequate in proportion or fair in representation. They also question whether civil society interests are genuinely represented, as some members sometimes do not seem to represent what they stand for. For example, in the VPA steering committee, civil society elected who should be their representatives whereas in REDD+ steering committee civil society members were directly picked by the government.

Civil society members and organisations are informed about consultation meetings through email or letter. They are also notified about it through civil society platforms such as Forest Watch Ghana. While it is not always the case, they are often provided soft copies of the draft reports before the consultation meetings. The minutes and reports are shared but these are not directly made available to a broader group (unless shared by civil society representatives in the working group or platform like the Forest Watch).

Many interviewees agree that women, customary authorities, forest communities and local communities are the groups who have been left out in REDD+ and VPA processes (mainly due to their limited capacity and confidence). Formal representatives from the local communities are still lacking in the steering committee for both VPA and REDD+ and, as the interviews reveal, they rarely engage with government agencies such as the Forestry Commission Ghana. Furthermore, there is also a distinct disconnect between national and local representations despite local communities often being their constituencies. Similarly, women groups have not been specifically targeted but they are brought on board when required. Unlike in the VPA, the private sector also has been left out in REDD+, as it is not specifically targeted at them. Similarly, other civil society members working on crosscutting issues such as tenure, land and mining seem to have been left out, as the focus has been on forestry sector. However, there has been some information sharing lately with a range of these groups.

The experience of civil society participation in VPA and REDD+ processes also varies. While the VPA was participatory, REDD + is not up to the same standard although some civil society members think that lately it is picking up lessons from the VPA. Many civil society members in Ghana even argue that there is literally a physical wall between the Climate Change Unit, REDD+ Steering Committee and the FLEGT VPA Steering Committee with no sharing of information and communication between these agencies. As a result, good practice and lessons learnt are rarely exchanged. Moreover, these agencies and civil society talk about the same issue but in different language (for e.g. governance is talked in terms of timber in VPA and in REDD+ in terms of carbon). 
Most interviewees think that civil society participation in VPA was particularly high (7 responses) or very high (2 responses), as civil society actors were involved from the beginning of the process. They also point out that they have been able to get on board the issues they raised during the VPA negotiation and consultation meetings, including issues of community rights; benefit sharing; and governance. ${ }^{6}$ In fact, governance working group during the VPA negotiation was coordinated by civil society members so the texts reflect a lot of their concerns. A few interviewees further argue that even non-NGO members were brought together and information shared, who then contributed to what goes where in the negotiated texts of the VPA document; hence VPA was very consultative.

However, many CSOs do not see a clear role for participation in the VPA implementation, which they seem happy to have opted out from. They argue that their main concerns are with governance and rights rather than issues of legality so they are not interested in doing audits. Civil society in Ghana is thus happy with its advocacy role in looking into social issues and leave the certification and auditing to independent third party monitors. Unlike in Liberia (and also in Indonesia), civil society in Ghana is thus outside of the auditing system and their role is as a 'watchdog' only. However, they are represented in other committees with some implementation roles such as the Timber Validation Committee, multi-stakeholder implementation committee and joint monitoring review mechanism (equivalent to joint implementation committee in some countries).

One of the issues that was raised during the VPA negotiations and which was successfully excluded from the VPA legality definition, which has resurfaced prominently (as observed in Forest Watch quarterly meeting) was the issue of 'special ministerial permits'. While timber rights and FLEGT license contracts can only be issued through a competitive bidding process, 'special permit' can be issued by the minister-in-charge without following laws for concession rights and without needing a parliamentary approval. As this is a potential loophole, NGOs had argued that special permits should be excluded from the VPA legality grid and hence timber with these permits could not be legally traded. The minister-in-charge at that time had argued for reinstating the special permits into the VPA legality grid. Following effective advocacy of Ghanaian NGOs, this issue was resolved.

Almost all the interviewees think that their experience with REDD+ has not been comparable with that of the VPA; the level of their participation in REDD+ was rated low (6 responses) to medium (3 responses). They were not invited for consultation in the early days of REDD+, however it has improved a bit lately. As one interviewee puts it:

REDD + in the beginning had a serious gap, as there was not enough time for consultation. Forestry Commission Ghana rushed into the pressure from the World Bank to prepare and finalise the R-PIN document. It did not really consult and there were a lot of complaints and contestations from the civil society (e.g. on how drivers of deforestation were defined) blocking its approval and asking to slow down the process. Even for the RPP, the government was in a hurry to complete things because monetary incentives from the World Bank were involved. RPP was contracted out to external consultants but when it came back some views of civil society were incorporated after consultation. They consulted but it was not enough...Moving forward since the RPP was approved, I think that some efforts have been made, with national REDD+ working group having a civil society representation. Participation on REDD+ strategy development has been fairly good but it is moderate, as some of the concerns raised by the civil society were not reflected in the final document.

\footnotetext{
${ }^{6}$ Also see Carlsen (2014) for an analysis of narrative techniques used by different Ghanaian NGOs in FLEGT VPA. For example, current tenure and uncontrolled domestic supplies are used as part of their narrative to highlight the need for legal reform, in which civil society can be a key player. Civil society actors also link the multi-stakeholder processes to change in forest governance across West and Central Africa, with an assumption that the process will mobilise civil society in the whole region.
} 
In VPA, the CSO experience of satisfaction range from very satisfied (2 responses), satisfied (5 responses) to neither satisfied nor unsatisfied (2 responses). In REDD+, the responses range from unsatisfied (5 responses), neither satisfied nor unsatisfied (2 responses) to satisfied (2 responses). Overall, most interviewees agree that the civil society participation has been encouraging in Ghana; they want more effective participation in forest governance and other areas of national policymaking.

However, achieving full and effective participation of civil society in policy processes is not easy, as one interviewee from an INGO involved in REDD+ development and implementation in Ghana cautions:

How many consultations do you do? If your representative is not putting the whole group views, whom should you blame?....Civil society is so diverse. There are so many types. There are only few genuine CSOs working in forests, mines, and natural resources; there are too many one-man NGOs. Who do you consult? There is also no clear framework on how civil society is to be mobilised and what entry point government or others can use? This is a challenge. Sometimes we have to be selective and ask those civil society members who can contribute. Definitely you cannot involve everyone but you have to target selectively. Unfortunately, it is sometimes the same people that you are consulting mostly.

\section{Liberia}

Among the studied countries, Liberia is the only country that achieved participation by CSOs and, separately, by 'communities' in the VPA negotiation and implementation. Thus, 'communities' have been acknowledged as distinct stakeholder group in the country's VPA process. Communities are also represented in the VPA steering committee. Whilst there was some measure of institutionalisation within communities to select/elect their representatives, and the whole process of doing so was facilitated by CSOs, those involved would not identify themselves as from community-based organisations, but simply from 'communities'. For example, the Union of Community Forestry Development Committees started its involvement in 2009 and became active after 2011. The Union strongly supports the VPA and thinks that the communities' views are incorporated in the final document.

Most CSOs argue that no groups have been deliberately left out of both VPA and REDD+ meetings. However, they point out the challenges some groups (e.g. local communities and women) experience in participating and following discussions in these meetings. In words of one interviewee, "there also exists a big gap between few CSOs who know and who do not know in terms of VPA and REDD+ issues". There have also been efforts lately to bring other stakeholders such as the National Chainsaw Union, National Charcoal Union and industries/private sector into discussion meetings.

The assessment of the REDD+ process is markedly different from community groups' experience with the VPA. They argue that they have not been fairly represented (e.g. in the working group of REDD+) and their main concern relating to the benefit sharing mechanism for communities has not been addressed. As one community representative argues:

For VPA our participation through to negotiation stage was empowering and fun but for REDD+ there is no such opportunity, even we cannot go back to the community and ask for their views. Additionally, the issues talked about in REDD+ are too technical for communities to understand. Nobody knows why you are sitting down there. The whole REDD+ structure should do more to provide a useful platform for community participation in Liberia. Additionally, REDD+ is contentious because there are associated costs to local 
communities. How do you address land tenure? How do you compensate local people displaced by REDD+ projects and private companies doing carbon trade?

This view is also shared by many national CSOs in Liberia. Most of the interviewees agree that the issue of civil society participation in REDD+ is a recent phenomenon, as "things are just beginning to happen". From their experience in participation in REDD+ so far, they argue that REDD+ is a very complex and abstract policy that contains a number of technical issues and concepts that they are not always familiar with. Articulating about REDD+ is thus a challenge for them. Additionally, there is also less funding and few incentives to participation in REDD+ as compared to the VPA.

A majority of CSO members argue that most consultations in policy processes in Liberia are done only for the purpose of validation - hence their overall experience of participation in VPA and REDD+ alike is only medium level. Despite this, they acknowledge that they have been successful in incorporating some of the civil society issues in national forest policies and VPA negotiation. Some examples include: recognition of customary rights and community entitlements to forests and widening the definition of 'illegal timber'. Some interviewees think that participation has been institutionalised in Liberia due to continuous demand from the civil society although government sometimes tend to use it only to legitimise its policy making.

Out of 10 responses, the assessment by most CSOs of their experience of participation in VPA is medium (3) to high (7) whereas their experience in REDD+ ranges from low (7 responses) to medium (3 responses). REDD+ meetings were considered only for information sharing in some cases due to the reason that most of the earlier meetings were technical and relevant stakeholders were not asked for participation. There has been more involvement of CSOs lately, particularly after 2013.

There was a lot of criticism and lack of trust in the beginning of REDD+ process in Liberia. For example, Sustainable Development Institute was very critical about any mechanisms of carbon trading initially, however it got involved in the preparation of the RPP. Among other things, CSOs highlighted issues of community rights (e.g. potential eviction from REDD+ projects) and benefit sharing (e.g. community access to bush meat). However, there were some disagreements between the civil society members and the government (also the consultant and World Bank). When the final document came out, views from Sustainable Development Institute and other CSOs were not incorporated. Hence CSOs opted out and said they were not part of the process. They asked to add a disclaimer explicitly stating that the CSOs did not approve the document. From that point onwards, the discussion on REDD+ was focused on entering carbon markets, in which many CSOs had lost interest in engaging in. More recently when the REDD+ process began to discuss measures such as forest law enforcement, governance and legality, CSOs found it useful to participate and are now involved in the development of the REDD+ strategy and the SESA Working Group.

Most CSOs consider their participation in VPA and REDD+ as both ongoing (regular) and ad hoc due to the nature of the meetings that take place. Besides regular meetings, there are sometimes emergency meetings organised based on urgency (e.g. finalisation of RPP). However, participation in REDD+ is 'scattered', fragmented and non-consistent. The CSOs also criticize the way information for meetings is provided at short notice and they are asked to review large documents. They do not get enough time to read in advance of the meeting and also, not all CSO members understand REDD+ jargon terms like reference level, carbon trading etc.

In terms of their satisfaction level, most CSOs are satisfied (7 responses) and some very satisfied (3 responses) with the opportunities of participation in VPA whereas in REDD+ their experience ranges: dissatisfied (5 responses), neither satisfied nor dissatisfied (3 responses) or satisfied (2 responses). 
It is also important to note the views of government. Although local communities and their representatives were missed out initially in REDD + , a government representative argued that the working group has been restructured to include them through the Government's Community Forestry Working Group. According to the REDD+ Implementing Unit, there have been so far 15 different national and regional consultations with regard to REDD+ and there is a fair representation of CSOs. However, the government's view is that there is some decline in CSO's visibility and influence lately, which sometimes can present as 'participation fatigue'. The government interviewee further points to the organisational capacity needs assessment and focused approach to work of CSOs in Liberia. Rather than having different types of NGOs bundled together to make an NGO Coalition, in the government's view, it would be helpful to have multiple coalitions working on different sectors (including one on forest governance) with more focused areas of work.

The government's claims of information sharing and increased participation are challenged by many CSOs who argue that accessing information from the Forest Development Authority has been difficult. Although there is a Freedom of Information Act in Liberia, they complain that the government does not comply with it. For example, one CSO asked for information in December 2015 but was still waiting for the information to be shared in March 2016. Hence CSOs demand more transparency in information sharing and want the provisions in the Act to be followed fully.

\section{Republic of Congo}

With regard to the VPA process, most of the CSOs were involved in negotiation, discussion and validation through the PGDF platform and the process was found to be intense and constructive by them. As one interviewee argues, in the VPA process most of the time the "CSO representatives were in the driving seat with their control of the issues being discussed". By contrast, attendance at REDD+ meetings was organised based on the government's preference and only those persons who 'cooperated' with the government's agenda and interest were invited.

Most of the interviewees thought that FLEGT VPA provided a multi-stakeholder platform through PGDF in which all stakeholders (including CSOs, indigenous peoples and local communities) were represented fairly. While they consider their participation in VPA negotiation, joint working group meetings, and discussion of the draft forest law and forest policies to be quite fruitful, they think that their participation in REDD+ meetings is for validation purpose only. As a result, CSO participants had no powers to block a document when there were disagreements in REDD+ meetings. Most CSOs think that REDD+ meetings were instead heavily dominated by the government administration while local communities and indigenous people were conspicuously missing or excluded. Local communities were also not present through VPA negotiation and implementation meetings.

When asked about the time of the policy cycle when CSOs are invited for participation, most of the interviewees agreed that this happens during policy development (even before policy development in the case of VPA for some interviewees). While CSOs were involved during all key stages of FLEGT VPA (e.g. including legality definition, traceability system and the independent forest observatory project), for REDD+ they were asked to participate only in validation workshops (e.g. for adoption of REDD+ strategy, RPP, R-PIN and ER-PIN).

For most interviewees, their participation in VPA is an ongoing process (6 responses) whereas REDD+ is an ad-hoc process (6 responses). The way CSOs are invited for participation in meetings also varies. Some CSOs were part of working groups such as the legal working group for REDD+ and FLEGT and they produced CSO proposals for negotiating documents (e.g. VPA and RPP). 
Others were invited because they were either part of the national consultative group or members of the joint working group, technical secretariat or communication working group.

A majority of the interviewees think that they are invited often (7 responses) to REDD+ meetings whereas in FLEGT the frequency at which CSOs are invited is comparatively higher, with 1 response for always, 3 responses for mostly and 4 responses for often. Usually, the CSOs are invited through phone calls, letters or emails; the information is not put into the public domain (e.g. media). Some CSOs learn about the event through platforms such as the PGDF and CACO-REDD, or through third parties.

The available information on meetings was thought to be complete, timely and understandable to most interviewees ( 7 responses) in the case of VPA whereas for REDD+ it was not the case for the majority of interviewees (6 responses).

For FLEGT, most CSOs thought that their views were considered in the final version of the VPA, as their contributions are often taken seriously. CSOs use different strategies to make their concerns heard; they take up the issue through active deliberations in the meetings or outside of the meetings through position papers and lobbying both national and internationally. ${ }^{7}$ However, in REDD+ CSOs experienced difficulties integrating their views due to weak consultations, most particularly during the development of RPP. Additionally, in most of the REDD+ consultations CSOs were not given sufficient time or resources to prepare for the meetings. As a result, their participation was far from being effective; it was more formal, standardised, and at times, 'staged'.

In the views of many interviewees, the REDD+ and FLEGT processes have not generally involved local communities and indigenous peoples; it is usually the CSOs who have to speak on their behalf. The only effective consultation that took place at the grassroots level was during the process for the revision of the Forest Code. Some interviewees even think that consultation meetings still have the connotation of party representations, often dominated by influential CSO members, and usually men. Although a platform like CACO-REDD has provisions for both civil society and indigenous peoples, community groups feel that the current set-up does not permit them to be autonomous or self-reliant, but it puts them under the authority of the civil society component. One interviewee even questions the holding of participation space by influential elite community members who do not necessarily represent grassroots views or work for community interests. ${ }^{8}$

All of the CSO interviewees agreed that the level of their participation in FLEGT processes was high/collaborating ( 7 responses) to very high/empowering (1 response). In the case of REDD+, there was mixed categorisation of their overall participation level: non-participation (1 response); informing/very low (4 responses); and consulting/low (3 responses). Overall, REDD+ experience was not comparable to VPA for a majority of CSOs, as participation was only offered to them after a strong protest and demand. For example, the CSOs first blocked the development of RPP, as it had published a position paper with disagreements over their level of participation. The government came back and discussed the document with participation of the CSOs that was later validated after most of the inputs from civil society were taken in to account.

\footnotetext{
${ }^{7}$ As one CSO member shares his experience: "within the framework of the revision for the Forest Code as required by the FLEGT VPA, the government wanted to pass a version of the code that did not go through consultation for CSOs and communities. During the first meeting of the multi-stakeholder consultative committee (CCM) in May 2013, I was charged to talk about the quality and legitimacy of the text proposed by the government. We did not recognise the document, which led to a redoing of the document with a real consultation with the communities. Additionally, we threatened to pull out from the CCM if the question of conversion timber was not put in the discussion agenda. After the presentation of this issue, the debates that followed led the minister in-charge of forests to recognise that there was a problem and our proposal to consider conversion timber in the revised forest law got approved".

${ }^{8}$ The interviewee also argues whether having representation in the meeting can be considered as participation: "within the framework of REDD+, it is true that the indigenous people option is put forward but one can pose the question if presence in a meeting without saying a single word means participating in the name of a group. To have their voice heard, indigenous people and local communities should be given necessary training on how to speak and put their views more effectively".
} 
The overall experience of civil society participation in FLEGT process ranged from satisfied (6 responses) or very satisfied (1 response) to neither satisfied nor dissatisfied (1 response). In REDD+, the overall experience was unsatisfied (6 responses) or neither satisfied nor dissatisfied (2 responses).

\section{Discussion}

The results illustrated some of the ways that participation has differed across countries and between REDD+ and FLEGT initiatives. While each country was different, there is an overall indication that local community and civil society representatives felt that FLEGT has been more participatory than REDD+. In this section, I unpack some of this data to understand whether or not there are specific features of the REDD+ and FLEGT governance arrangements that detracted from or encouraged the participation of these groups. In my introduction, I explored some of the ways that REDD+ and FLEGT can, and cannot, be compared. I now analyse the findings based on some of these features, to understand whether or not they have an influence on how space is made for participation.

There is a growing recognition of civil society participation in national policy making of forest governance in Cameroon, Ghana, Liberia and the Republic of Congo, and a majority of the CSOs in these countries are participating in REDD+ and FLEGT VPA processes. However, some civil society actors are more involved in one area than another (i.e. between the two forest governance mechanisms) and the quality of participation varies among these actors and the studied countries. Although most of the interviewees were civil society actors themselves and they will positively value their participation for obvious reasons, their role in national policy making of forest governance has also been acknowledged by external non-civil society actors (for example, by government representatives in Liberia and INGO actors in Ghana).

However, the degree of participation varies considerably across countries depending on the perception of the CSO actors interviewed. For example, in Cameroon and in Republic of Congo, there are two different platforms that often do not share the same vision and have different perceptions about the importance and effectiveness of their participation. This is complicated by existing conflicts between the CSOs or history of 'no cooperation' between the government and civil society. This highlights the different interests at stake in the process of participation and the complexity associated with the politics of participation (cf. Cornwall, 2008; White, 1996; Tegegne et al., 2017).

A common observation from the four case studies is that the FLEGT VPA process is more accommodative in terms of representation and participation of CSOs (with medium to high level of participation) whereas the experience of civil society participation in REDD+ policy process is generally low. There are various reasons to the low participation in REDD+ as compared to VPA. While VPA involves timber as the main commodity at stake (with which most actors in forest governance are familiar), REDD+ involves an abstract concept of carbon and involves complex bureaucracy and complicated terminologies such as greenhouse gas emissions, Measurement Reporting and Verification, reference levels, leakage and carbon trading.

As a number of earlier studies have also highlighted, domination of techno-bureaucracy is a paradox that forestry reform and new forest policies have accompanied in the name of participation (Lund, 2015; Hajjar, 2015; Green and Lund, 2015). While concerns of civil society and communities are focused on issues of land tenure, benefit sharing and community rights, the message being delivered from the government and implementing agencies is that REDD + is a technical issue rather than a governance one (Hajjar, 2015; Myers et al. 2018). There are also few tangible incentives (monetary and other) for the civil society and communities to participate in policy making for REDD+. 
Many interviewees across the four countries also appreciated the fact that FLEGT required their involvement from the beginning while they were invited in REDD+ events at the last minute (just to validate the documents). Civil society participation in REDD+ is thus ad hoc and purpose-led, which is in contrast to long-term and continued participation in VPA. In particular, participation was much higher in the VPA negotiation phase. In REDD+ many actors across the four countries perceived their participation to be random and rushed. It is common across all the countries studied that prior notification of meetings is rarely given on time to the civil society members. They are not expected to just go to attend meetings and legitimise the policy process without proper preparation and consulting widely with their group and constituents. The recently developed government- CSO consultative framework in Ghana is a positive example. Under the provisions in this framework, it is required that civil society is notified of a regular meeting two weeks in advance and for special or emergency meeting, the requirement is three days' prior notice. The adoption of FPIC national guidelines in Cameroon is another good example. The guidelines have been developed in a participatory way in order to enhance stakeholder engagement in the REDD+ process, however the problem is that these guidelines are not applied, cautioning a gap between procedural (process) aspect of participation and its output (consequential) aspect (Balest et al., 2017; see also Myers et al., 2016).

This study also highlights the disconnects between the two forest governance initiatives as the lessons learnt have been rarely shared between different government departments and among actors (see also Hajjar, 2015 on challenges of complementarity between FLEGT and REDD+ in Ghana). Despite a favourable experience with the VPA process and a mostly successful effort to ensure civil society participation in the study countries, only a few good practices have been taken up in the REDD+ process. On the other hand, the fact that civil society representatives in the participation at the VPA process are more critical of their participation experience in REDD+ process illustrates some integration of lessons learnt by civil society actors. As actors they have become more vocal, critical and able to develop a coherent analysis and defend it. However, more needs to be done to address institutional disconnect between the REDD+ and VPA processes.

Despite the wide application of deliberative approaches, there remains a gap between the idealistic objective and actual implementation of participatory approaches. The analysis shows that participation has not been mainstreamed in the four countries studied although it is more common than a few years ago. Overall, the frequency of civil society participation in national policy making is inconsistent. As civil society actors in these countries highlight, desirable participation is when they are involved from the beginning of a policy process, their inputs are discussed, accepted or rejected 'but taken seriously into consideration'. Therefore, there is a need to enhance participation in decision-making, most particularly in the REDD+ process, by involving civil society and communities from the outset in the design, development and implementation of policies and actions. Engaging the CSOs from early in policy development can increase their confidence and skills. For example, even though the VPA was technical (often requiring legal knowledge), because many CSOs were involved from the beginning (i.e. felt represented) they got an opportunity to increase their awareness and participate effectively; whereas REDD+ has not been able to provide the same level of experience. These examples corroborate similar findings that early involvement is a prerequisite for meaningful participation (see for example, Balest et al., 2017; Kangas et al., 2014).

Among other stakeholder groups, representation of the local communities and indigenous groups in particular is lacking in both VPA and REDD+ processes (except in the VPA process in Liberia) (see also, Tegegne et al., 2017 and Hajjar, 2015 for similar findings in Cameroon and Ghana respectively). In the four countries of study, there is also a low level of participation of the vulnerable groups, particularly the poor forest people, women and youth. Although civil society 
platforms recognise this gap and progress has been made, more needs to be done. More specifically, there is a need to ensure and enable representation of local communities and indigenous people at higher levels by their own selected/elected representatives and also to link the national CSOs better with the grassroots. The low level of their participation also highlights the limitations of international processes such as REDD + and EU-VPA by their basic design in ensuring equitable and socially beneficial outcomes. For example, REDD + safeguards are only guidelines and not something that one can hold the state or others to account to. ${ }^{9}$

Although most of the civil society participation occurs through specific platforms (i.e. through semi-direct to indirect participation) that are recognised in these countries, wider participation depends on the process and the way these platforms have been organised, including the rules and criteria for membership, institutional and organisational structures of CSOs and platforms, internal accountability and selection process etc. Furthermore, as reflected in the analysis of individual countries, although civil society groups are represented in the steering committee for REDD + and VPA and other working groups, there are sometimes questions whether or how representatives represent the views of civil society organisations, the people they claim to represent, or just represent themselves (see also, Weber, 2017; Johansson, 2016). In some cases, civil society representatives are picked by the government, which can not only create distrust and division between the civil society but is also an important barrier to genuine participation and effective representation (cf. Cornwall, 2008; White, 1996). In other cases, the basis for internal selection of participants by civil society platforms is based on some criteria, such as responsibilities, competence and expertise on the subject matter, which sometimes favours the participation of the same (already influential) people going to different meetings (cf. Cooke and Kothari, 2001; Cornwall, 2008).

Level of trust in other actors is one of the key aspects evaluated in many studies on participation (see, for example, Brescancin et al., 2017; Kangas et al., 2014). As observed in this study, the collaboration between the government and CSOs in the four countries of studies is generally quite poor and needs strengthening. However, NGOs would generally argue that the collaboration has increased massively through the VPA process (see Fern, 2013). While CSOs consider themselves to be complementing the government efforts (as the government has not all the human, material and financial resources), they feel that the government looks at the CSOs with suspicion and considers them as their opposition. This was a recurring issue for CFP in Cameroon and was also raised by some CSOs in Ghana and Liberia.

CSOs are themselves divided in their views and do not always pursue common goals (for example in Cameroon and the Republic of Congo). Sometimes, they compete and exclude one another for reasons of funding, reputation and interest. They are also very diversified in terms of their interests, size, capacity, sources of funding, influence, networks and so on. In particular, there is a common problem of capacity deficit among the CSOs in the case study countries (see also Ameyaw et al., 2016 for key capabilities challenges among forestry professionals in Ghana). Only through access to resources such as information, knowledge and skills can the participants defend their interests and effectively influence the final decisions (Balest et al., 2017). As Cornwall (2008, p. 275) cautions, "while opening spaces for dialogue through invitation is necessary, it is by no means sufficient to ensure effective participation. Much depends on how people take up and make use of what is on offer, as well as on supportive processes that can help build capacity, nurture voice and enable people to empower themselves".

\footnotetext{
${ }^{9}$ However, it is worth mentioning that delivery partners, such as UN-REDD and Forest Carbon Partnership Facility (FCPF) of the World Bank, can backstop countries in the REDD+ progress. For example, Cameroon and the Republic of Congo have had their RPPs and ER-PIN not approved during Participant Committee meetings due to the countries not including key CSO groups in the elaboration of those documents.
} 
Hence it is important that participatory spaces and platforms are not only consolidated but transparent and that CSO structures are not only well functioning but also inclusive and accountable so that they are open to accommodate a diversity of voices from its members (Satyal et al., 2018). It also needs to be noted that in some countries when civil society actors are successful in having their voices heard they are confronted with a lot of pushback and attempts to be silenced. Competing civil society actors with opposite interests are often instrumental in neutralising and even oppressing the most critical civil society voices (e.g. the case of CFP in Cameroon). As a result, space for dialogue gained at some moment risks to be lost a bit later. It thus requires a long-term investment and commitment to maintain and enhance the level of participation.

Finally, participation is not just a tick-box exercise. It requires sufficient time, resources, adequate organisation and a clear decision-making framework to conducting participation in a full and effective manner (Kangas et al., 2014; Teder and Kaimre, 2017; Balest et al., 2017). As highlighted by many interviewees in the four case study countries, CSOs are tired of the endless discussions and meetings that take place; they instead want a meaningful participation process (Lindstad, 2017). For this, they stress the need to focus on the quality of their participation rather than the quantity (i.e. taking control of the decision-making and making their participation more about collaboration and empowerment rather than having a number of meetings where their role is just to listen). They also highlight the need to promote more participatory processes and structures across all levels in order to involve civil society more actively in the policy design, implementation and monitoring. Additionally, the decision-making processes will need to relate to each other across scales, (local to global), taking a nested approach to civil society participation (Atela et al., 2016).

\section{Conclusion}

Using an assessment tool developed from a wider literature on participation, this paper compared and contrasted the level of civil society participation in two influential forest governance initiatives - FLEGT and REDD+ in four countries of Central and Western Africa. I discussed a number of issues that can enhance or constrain civil society participation. Despite different contexts and the status of civil society actors, there have been increasing instances of civil society participation in the four countries of study, but there remains a gap between utopian objective of participation and its practical implementation. I noted a major difference in experience of participation among the civil society actors across FLEGT and REDD+ processes. I argued that the main reason for this is due to the subject matter of forest policy consultations and the commodity at stake. While FLEGT involves discussion about timber, a commodity that various actors understand and in which they have been already involved, REDD+ involves abstract concepts of carbon and its markets that do not exist yet. The technical nature of consultations and complexity of REDD+ terminologies are also difficult to comprehend and can be uninteresting for some civil society actors. Similarly, while actors involved might be similar at policy making levels, they are quite different at local levels; FLEGT involving private companies which is not necessarily the case with the REDD + . The difference in participation level between REDD+ and VPA is also related to the design of these two processes and the general lack of time and financial investment in REDD+ development and implementation. VPA has been more inclusive and participatory right from the beginning of the process whereas participatory spaces are generally lacking in REDD+ process, most particularly in its initial stages.

This research provides some useful policy insights for many countries where FLEGT and REDD+ are being rolled out. There are also useful lessons to be learnt between these two forest governance initiatives (e.g. why FLEGT VPA was considered more participatory than REDD+ by most civil society actors). While participation is not panacea to all kinds of forest governance problems, it operates as a set of governing practices that enable state and non-state actors to inform perceptions and preferences, and also help introduce policy reform and change in a variety of settings. I argue 
that a progressive vision for forest policy making should be based on principles of transparency, accountability and information sharing and decision-making processes under both FLEGT and REDD+ should provide equal opportunity and space for participation of all kinds of non-state actors (see also, Satyal et al., 2018). The more technical the project, the more difficult engaging a wide range of actors might be, especially when tangible incentives are not evident (see also Myers et al. 2018). Diverse political economy and different institutional settings under which national policy processes take place in each country also influence the level of civil society participation. We need to acknowledge that processes like FLEGT and REDD+ happen in the context of political economies that go beyond the bubble of stakeholder processes orchestrated by donors such as the European Union, United Nations and the World Bank. Consequently, the level of inclusiveness and mechanism of participation differ country by country based on the national conditions and contextual specificities, such as system of land tenure and forestry laws (Balest et al., 2017; Kangas et al., 2014; Wodschow et al., 2017). FLEGT and REDD+ have a potential to go beyond what has been done before, by using innovative means of participation and building on the lessons learnt from the experiences so far.

The assessment tool that was used in this study can be replicated and adapted for use in similar policy contexts elsewhere. Different degrees of participation as discussed in the paper (i.e. informing - very low influence; consulting - low/some influence; involving - medium influence; collaborating - high/much influence; and empowerment - very high influence) demonstrate the methodological usefulness of the assessment criteria (see also, Teder and Kaimre, 2017; cf. Arnstein, 1967). Although this study focused on examining the experience of civil society actors, it would be useful to know more detailed views of diverse actors such as the implementing agencies, government, private sector and communities of different kinds. The results of this study can be an important starting point for future research aimed at evaluating different opinions and perceptions of a variety of actors in national policy making. Similarly, while the focus of this assessment was participation in policy development and policy making, it is equally important to consider how participation takes place in implementation (e.g. VPA compliance and implementation, monitoring of social agreements and safeguards, community benefit sharing etc.). The influence of different political economies (including social conditions, tenure and forest laws) on participation also warrants further evaluation.

\section{Acknowledgements}

Financial assistance for this study was provided through a grant from the European Union and the University of East Anglia. The author would like to thank Fern and its in-country partners for their support during the field work and Samuel Nnah Ndobe for providing research assistance and covering part of field study in Cameroon and the Republic of Congo. Thanks are also due to Rodd Myers, Saskia Ozinga, Grainne Kennedy as well as four anonymous reviewers and editors of the Forest Policy and Economics for their very useful comments on earlier drafts of the paper. 


\section{References}

Agarwal, B. (2001) 'Participatory exclusions, community forestry, and gender: an analysis for South Asia and a conceptual framework', World Development 29(10): 1623-1648.

Agarwal, B. (2010) 'Does women's proportional strength affect their participation? Governing local forests in South Asia', World Development 38(1): 98-112.

Agora Consulting (2015) Survey on Existing Dialogue Frameworks in Cameroon. Accessed on 5 January 2017 at: http://pasccmr.org/sites/default/files/fichiersrapportactiv/Survey\%20on\%20existing\%20dialogue $\% 20 \mathrm{fr}$ ameworks\%20in\%20Cameroon\%20-\%20April\%202015 0.pdf

Ameyaw, J., Arts, B. and Wals, A. (2016) 'Challenges to responsible forest governance in Ghana and its implications for professional education', Forest Policy and Economics, 62: 78-87.

Arnstein, S.R. (1969) 'A Ladder of Citizen Participation', Journal of the American Institute of Planners 35(4): 216-224.

Atela, J.O., Quinn, C.H., Minang, P.A., Duguma, L.A. and Houdet, J.A. (2016) 'Implementing REDD + at the national level: stakeholder engagement and policy coherences between REDD+ rules and Kenya's sectoral policies', Forest Policy and Economics, 65: 37-46.

Atuobi, S. (2010) State-Civil Society Interface in Liberia's Post-Conflict Peacebuilding. Accessed on 5 January 2017 at: http://www.kaiptc.org/Publications/OccasionalPapers/Documents/Occasional-Paper-30-Atuobi.aspx

Balest, J., Hrib, M., Dobsin, Z., Paletto, A. (2017) 'The formulation of the national forest programme in the Czech Republic: A qualitative survey, Forest Policy and Economics, http://dx.doi.org/10.1016/j.forpol.2017.02.002

Borrini-Feyerabend, G. (1997) Beyond Fences: Seeking Social Sustainability in Conservation, IUCN, Gland.

Brescancin, F., Dobsinska, Z., Meo, I.D., Salka, J. and Paletto, A. (2017) 'Analysis of stakeholders' involvement in the implementation of the Nature 200 network in Slovakia', Forest Policy and Economics, http://dx.doi.org/10.1016/j.forpol.2017.03.013

Brochaus, M., Gregorio, M.D. and Mardiah, S. (2014) 'Governing the design of national REDD+: an analysis of the power of agency', Forest Policy and Economics, 49: 23-33.

Broekhoven, G., Wit, M., Goransson, E., John, R. and Van, C. (2014) Linking FLEGT and REDD+ to improve forest governance-a synthesis. ETFRN Newsletter 55, March.

Carlsen, K. (2014) 'Constructing a legitimate argument- narrative techniques in the Ghana-EU VPA, Forest Policy and Economics, 48: 63-71.

Carodenuto, S. and Cerutti, P.O. (2014) 'Forest law enforcement, governance and trade (FLEGT) in Cameroon: Perceived private sector benefits from VPA implementation', Forest Policy and Economics 48: 55-62.

CIVICUS (2014) The State of Civil Society in Ghana: An Assessment, CIVICUS Civil Society Index Rapid Assessment Report. Accessed on 5 January 2017 at: http://civicus.org/images/stories/Ghana\%20CSI\%20RA\%20final.pdf

Cleaver, F. (1999) 'Paradoxes of participation: questioning participatory approaches to development', Journal of International Development 11: 597-612.

Cooke, B and Kothari U. (eds.) (2001) Participation: the New Tyranny, Zed Books, New York.

Cornwall, A. (2008) 'Unpacking 'participation': models, meanings and practices', Community Development Journal, 43(3): 269-283.

Counsell, S. (2009) Forest Governance in Africa, Occasional Paper No. 50, Governance of Africa's Resources Programme, South African Institute of International Affairs, Johannesburg, October 2009.

Dawson, N, Mason, M., Mwayafu, D., Dhungana, H., Satyal, P., Fisher, J., Zeitoun, M. \& Schroeder, H., 2018, "Barriers to equity in REDD+: deficiencies in national interpretation processes constrain adaptation to context', Environmental Science and Policy, 88, 1-9. 
Daviet, F. (2011) A Draft Framework for Sharing Approaches for Better Multi-Stakeholder Participation Practices, Forest Carbon Partnership Facility and UN-REDD Programme. Dooley, K., and Ozinga, S. (2011) 'Building on forest governance reforms through FLEGT: The best way of controlling forests' contribution to climate change?' Review of European Community and International Environmental Law 20(2) (July 1): 163-170.

Commission of European Communities (2003) Forest Law Enforcement, Governance and Trade (FLEGT): Proposal for an EU Action Plan: Communication from the Commission to the Council and the European Parliament. COM (Commission of the European Communities). Office for Official Publications of the European Communities.

Faysse, N. (2006) 'Troubles on the way: an analysis of the challenges faced by multi-stakeholder platforms', Natural Resources Forum 30: 219-229.

FCPF, \& UN-REDD (2012) Guidelines on stakeholder engagement in REDD+ readiness with a focus on the participation of indigenous peoples and other forest-dependent communities. Accessed on 8 August 2018 at: https://www.forestcarbonpartnership.org/sites/fcp/files/2013/May2013/Guidelines\%20on\%2 0Stakeholder $\% 20$ Engagement $\% 20$ April $\% 2020, \% 202012 \% 20$ (revision $\% 20$ of $\% 20 \mathrm{March} \% 2$ 025th\%20version).pdf

Fern (2013) Improving Forest Governance: A comparison of FLEGT VPAs and their impact. Accessed on 24 November 2016 at: http://www.fern.org/sites/fern.org/files/VPAComparison internet 0.pdf

Fern (2014a) Making Forestry Fairer: A practical guide for civil society organisations taking part in FLEGT VPA negotiations. Accessed on 24 November 2016 at: http://www.fern.org/sites/fern.org/files/makingforestryfairer internet.pdf

Fern (2014b) Community representation and participation in the VPA process: How communities from nine VPA countries are represented in the FLEGT VPA process. Accessed on 24 November 2016 at: http://www.fern.org/sites/fern.org/files/participationENG_internet.pdf

Forsyth, T. (2010) 'Multilevel, Multiactor Governance in REDD'. In: Angelsen, A., Brockhaus, M., Kanninen, M., Sills, E., Sunderlin, W., and Wertz-Kanounnikoff, S. (eds.) Realising REDD+: National Strategy and Policy Options, CIFOR, Bogor, Indonesia, 113-122 pp.

Gramberger, M. (2001) Citizens as Partners: OECD Handbook on Information, Consultation and Public Participation in Policy-Making, Organization for Economic Co-Operation and Development, Paris.

Green, K.E. and Lund, J.F. (2015) 'The politics of expertise in participatory forestry: a case from Tanzania', Forest Policy and Economics, 60: 27-34.

Hajjar, R. (2015) 'Advancing small-scale forestry under FLEGT and REDD in Ghana', Forest Policy and Economics, 58: 15-20.

Hughes, A. and Atampugre, N. (2005) 'Overview: a critical look at civil societies' poverty reduction monitoring and evaluation experiences', PLA Notes 51:1-10.

IAIA (2006) Public Participation: International Best Practice Principles, International Association for Impact Assessment, Fargo.

Johansson, J. (2016) 'Participation and deliberation in Swedish forest governance: the process of initiating a National Forest Program', Forest Policy and Economics, 70: 137-146.

Jumah, B. (2011) Towards Democratic Ownership in Ghana: Strong Progress in Civil Society. Accessed on 5 January 2017 at: http://alliance2015.org/fileadmin/Texte_Pdfs/Text_Documents/Ghana_Democratic_Owner ship country brief 2011.pdf

Kangas, A., Heikkila, J., Malmivaara-Lamsa, M. and Lofstrom, I. (2014) 'Case Puijo-Evaluation of a participatory urban forest planning process', Forest Policy and Economics, 45: 13-23.

KASA Ghana (2016) https://www.kasaghana.org/ (accessed October 2016).

Kozova, M., Dobsinska, Z., Pauditsova, E., Tomcikova, I. and Rakytova, I. (2017) 'Network and participatory governance in urban forestry: An assessment of examples from selected Slovakian cities', Forest Policy and Economics, 
http://dx.doi.org/10.1016/j.forpol.2016.09.016

Lawlor, K., Madeira, E., Blockhus, J., and Ganz, D. (2013) 'Community participation and benefits in REDD+: A review of initial outcomes and lessons', Forests 4(2): 296-318.

Lindstad, B.H. (2017) 'What's in it for me?' - Contrasting environmenmental organisations and forest owner participation as policies evolve', Forest Policy and Economics, http://dx.doi.org/10.1016/j.forpol.2017.01.003

Lund, J. F. (2015) 'Paradoxes of participation: The logic of professionalization in participatory forestry', Forest Policy and Economics, 60: 1-6.

Maier, C., Lindner, T. and Winkel, G. (2014) 'Stakeholders' perceptions of participation in forest policy’, Land Use Policy 39:166-176.

Maryadi, A. and Sahide, M.A.K. (2017) 'Research trend: power analyses in polycentric and multilevel forest governance', Forest Policy and Economics, 81: 65-68.

McKeown, M. and Mulbah, E. (2007) Civil Society in Liberia: Towards a Strategic Framework for Support. Accessed on 5 January 2017 at: https://www.sfcg.org/wpcontent/uploads/2014/08/LBR EV Apr07 Civil-Society-in-Liberia-Towards-a-StrategicFramework-for-Support.pdf

Mustalahti, I., Cramm, M., Ramcilovic-Suominen, S. and Tegegne, Y.T. (2017) 'Resources and rules of the game: Participation of civil society in REDD+ and FLEGT-VPA processes in Lao PDR. Forests, Trees and Livelihoods 8(2) (February 21): 50.

Myers, R., Sanders, A.M., Larson,A., Ravikumar, A., and Prasti H, R.D. (2016) Analyzing Multilevel Governance in Indonesia: Lessons for REDD+ through Land Use Change and Benefit Sharing in Central and West Kalimantan, Indonesia. Bogor: CIFOR.

Myers, R., Larson, A.M., Kowler, L., Yang, A., and Trench, T. (2018) 'Messiness of Global Project Governance: Lessons from Land Use Changes for REDD+', Global Environmental Change. https://doi.org/10.1016/j.gloenvcha.2018.02.015

Ochieng, R.M., Visseren-Hamakers, I.J. and Nketiah, K.S. (2013) 'Interaction between the FLEGTVPA and REDD+ in Ghana: Recommendations for interaction management', Forest Policy and Economics, 32 (July): 32-39.

Osmani, S. (2008) 'Participatory governance: an overview of issues and evidence', In: Participatory Governance and the Millennial Development Goals, United Nations, New York, 1-48 pp.

Overdevest, C. and Zeitlin, J. (2014) 'Constructing a transnational timber legality assurance regime: Architecture, accomplishments, challenges', Forest Policy and Economics, 48: 6-15.

Pham, T.T., Di Gregorio, M., Carmenta, R., Brockhaus, M. and Le, D.N. (2014) 'The REDD+ policy arena in Vietnam: participation of policy actor', Ecology and Society 19(2): 22. Phúc, T.X., Quyền, N.T., Phương, L.D. and Cẩm, C.T. (2012) 'Vietnam's wood villages: Relevance for FLEGT and REDD+'. Information Brief. Forest Trends.

Satyal, P., Corbera, E., Dawson, N., Dhungana, H.\& Maskey, G. (2018) 'Representation and participation in formulating Nepal's REDD+ approach', Climate Policy. Available online: https://www.tandfonline.com/doi/full/10.1080/14693062.2018.1473752

Secco, L., Da Re, R., Pettenella, D., and Gatto, P. (2014) 'Why and how to measure forest governance at local level: A set of indicators', Forest Policy and Economics 49: 57-71.

Shrestha, S. and Shrestha, U.B. (2017) 'Beyond money: Does REDD+ payment enhance household's participation in forest governance and management in Nepal's community forests?', Forest Policy and Economics, 80: 63-70.

Sikor, T., and To, P.X. (2014) 'Conflicts in Vietnam's forest areas: Implications for FLEGT and REDD’, ETFRN News, No. 55, March: 125-133.

Späth, J. (2015) Comparative Analysis of FLEGT and REDD+ Safeguards in Indonesia. University of Utrecht.

Stojanovska, M., Miovska, M., jovanovska, J. and Stojanovski, V. (2014) 'The process of forest management plans preparation in the Republic of Macedonia: Does it comprise governance principles of participation, transparency and accountability?', Forest Policy and Economics, 
49: 51-56.

Stoll-Kleemann, S. and O'Riordan, T. (2002) 'From participation to partnership in biodiversity protection', Society and Natural Resources 15:161-177.

Teder, M. and Kaimre, P. (2017) 'The participation of stakeholders in the policy processes and their satisfaction with results: A case of Estonian forestry policy', Forest Policy and Economics, http://dx.doi.org/10.1016/j.forpol.2017.05.007

Tegegne, Y.T., Ramcilovic-Suominen, S., Fobissie, K., Visseren-Hamakers, I.J., Lindner, M. and Kanninen, M. (2017) 'Synergies among social safeguards in FLEGT and REDD + in Cameroon', Forest Policy and Economics, 75: 1-11

Tikkanen, J. (2017) 'Participatory turn - and down-turn - in Finland's regional forest programme process', Forest Policy and Economics, http://dx.doi.org/10.1016/j.forpol.2017.04.009

Weber, N. (2017) 'Participation or involvement? Development of forest strategies on national and sub-national level in Germany', Forest Policy and Economics, http://dx.doi.org/10.1016/j.forpol.2017.04.002

White, S.C. (1996) 'Depoliticising development: The uses and abuses of participation', Development in Practice, 6:1, 6-15.

Wodschow, A., Nathan, I., Cerutti, P. (2016) 'Participation, public policy-making, and legitimacy in the EU Voluntary Partnership Agreement process: The Cameroon case', Forest Policy and Economics, 63: 1-10.

World Bank (1998) Participation and Social Assessment: Tools and Techniques, World Bank, Washington DC. 


\begin{tabular}{|c|c|}
\hline Structure of the tool & Main questions \\
\hline $\begin{array}{l}\text { Part I: General } \\
\text { information }\end{array}$ & $\begin{array}{l}\text { - Roles and main features of CSOs, including their main areas of } \\
\text { work } \\
\text { - CSO's involvement and familiarity with the REDD+ and/or FLEGT } \\
\text { VPA processes } \\
\text { - Whether and how pre-consultation within their own organisation or } \\
\text { community (before the national meeting) took place? How they } \\
\text { decided who would represent who in the meeting? }\end{array}$ \\
\hline $\begin{array}{l}\text { Part II: Who } \\
\text { participates? }\end{array}$ & $\begin{array}{l}\text { Did they participate in the development of any of the REDD+ } \\
\text { documents (e.g. RPIN -Readiness Plan Idea Note, the REDD } \\
\text { strategy, RPP-Readiness Preparation Proposal) and the ER-PIN- } \\
\text { Emissions Reduction Project Idea Note for Ghana, Cameroon and } \\
\text { Republic of Congo)? Did they approve any of these documents? } \\
\text { - Did they participate in the negotiation and adoption of the VPA? } \\
\text { Did they approve it? } \\
\text { - Do they think that the civil society stakeholders were fairly } \\
\text { represented in the REDD+ and FLEGT VPA processes? } \\
\text { Any important interests or stakeholder groups missed or excluded } \\
\text { in the REDD+ and FLEGT meetings? } \\
\text { Why do they think they were invited/ or were not invited to } \\
\text { participate in the meetings leading to approving the REDD+ and/or } \\
\text { FLEGT documents? }\end{array}$ \\
\hline $\begin{array}{l}\text { Part III: When they } \\
\text { participate? }\end{array}$ & $\begin{array}{l}\text { Time of participation: When were they asked for participation or } \\
\text { when did they demand participation (e.g. before/during/after policy } \\
\text { development)? } \\
\text { - What stage of REDD+ and/or FLEGT VPA document development } \\
\text { and approval have they participated in? } \\
\text { - Frequency of participation: Was their participation an ongoing } \\
\text { process or ad-hoc process? } \\
\text { - Duration of their participation: short/medium/long term? } \\
\text { - Institutional mechanism of their participation: were they a part of } \\
\text { working group for REDD+ and FLEGT? }\end{array}$ \\
\hline $\begin{array}{l}\text { Part IV: How they } \\
\text { participate? }\end{array}$ & $\begin{array}{l}\text { - Any evidence of manipulated, reluctant or forced participation? } \\
\text { - Whether they experienced participation 'fatigue' or burden (due to } \\
\text { requirements to comply with participation criteria or commit to } \\
\text { time and efforts)? } \\
\text { - How often were they informed about FLEGT and REDD+ meetings } \\
\text { (e.g. never/often/mostly/always)? } \\
\text { - When, by whom and how were they informed? How did they know } \\
\text { about the meeting? Was the information also in the public domain } \\
\text { (e.g. media, internet)? } \\
\text { - Was the available information on REDD+ and FLEGT meetings } \\
\text { provided in a complete, timely way and understandable to them? } \\
\text { Were they consulted to review and comment on texts/materials? } \\
\text { How do they rate the consultation process (e.g. } \\
\text { weak/moderate/strong)? }\end{array}$ \\
\hline
\end{tabular}




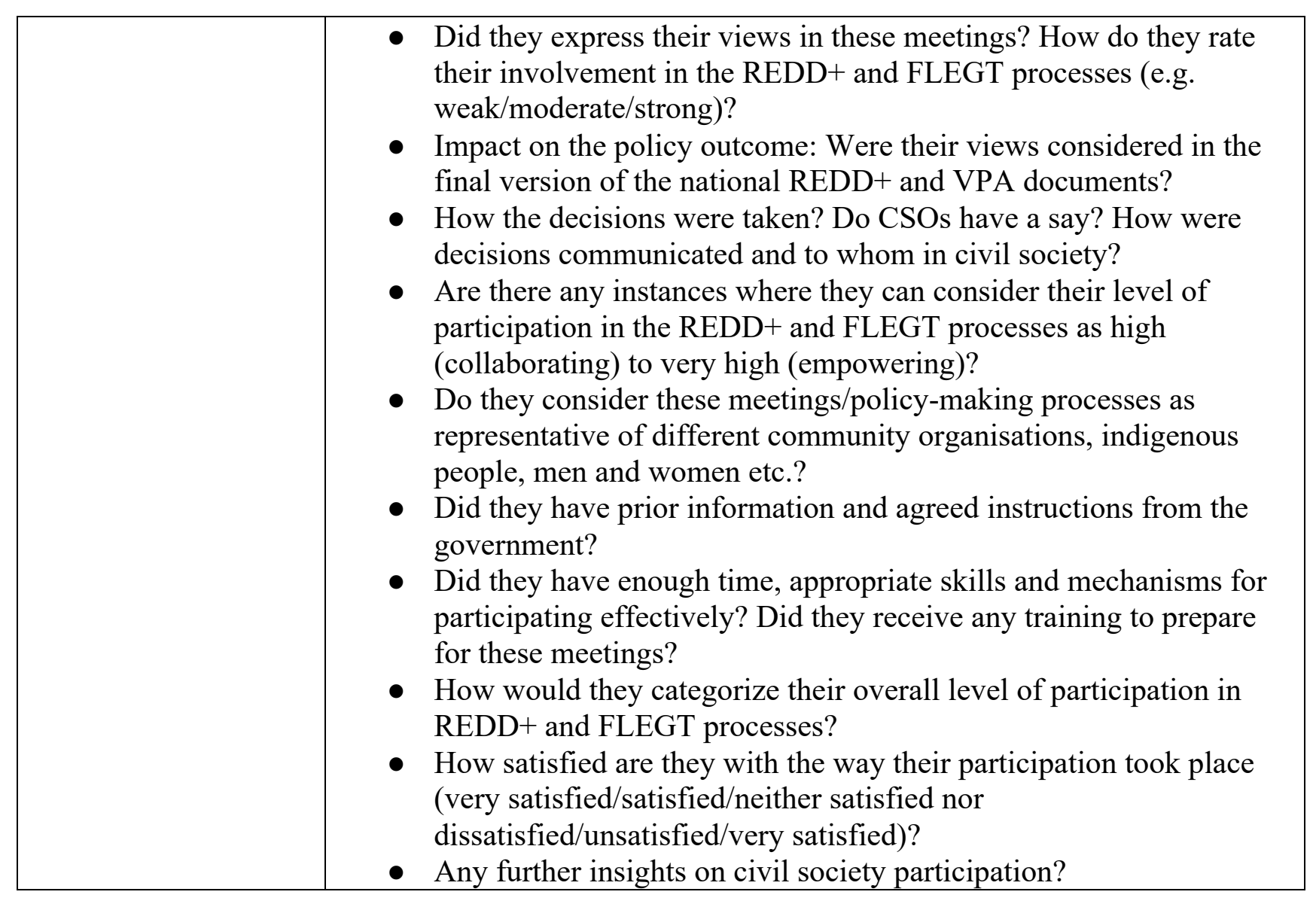

